LUBLIN STUDIES IN MODERN LANGUAGES AND

LITERATURE 40(1), 2016, HTTP://WWW.LSMLL.UMCS.LUBLIN.PL, HTTP://LSMLL.JOURNALS.UMCS.PL

\author{
Agnieszka Mierzwińska-Hajnos \\ Maria Curie-Skłodowska University \\ Plac Marii Curie-Skłodowskiej 5, \\ 20-031 Lublin, Poland
}

\title{
Conceptual Blending Revisited: A Case of Paraphrased Literary Text in Contemporary Advertising
}

\begin{abstract}
One of the successful tools used in creative contemporary advertising is the intentional modification of texts taken from popular literature (Gajewska 2011, also Bralczyk 2004). This paper offers a conceptual blending analysis of an advertisement for Ranigast $\AA$, a medicine used in the treatment of dyspepsia, which relies on a paraphrased fragment of The Sick Kitten, a famous Polish poem for children written by Stanisław Jachowicz. The linguistic analysis of the proposed advertisement will be carried out in the light of conceptual blending theory, in particular with the aid of Line Brandt and Per Aage Brandt's model of conceptual integration (Brandt and Brandt 2005) Assuming that each advertisement is, to some extent, an interplay between the speaker and the hearer, a particular emphasis is going to be laid upon the complexity of the so-called Semiotic Base Space which serves as a "prerequisite for meaning construction" in the analyzed ad (Brandt and Brandt 2005: 225). For further elaboration of the Semiotic Base Space, which I consider of vital importance for an analyzed instance, Ronald Langacker's notion of Current Discourse Space (Langacker 1999, 2001) as well as Esther Pascual's notions of the Verbal Space and Here-and-Now Space (Pascual 2009) will also be taken into account.
\end{abstract}


Keywords: conceptual blending, advertising, the Brandt and Brandt model, current discourse space

\section{Introduction}

Contemporary advertisements offer numerous techniques to capture the attention of a potential customer. To boost the selling power of a product, copywriters reach for various tools, both visual and verbal, thus making a given ad not only an interesting marketing device, but also a fascinating material for a linguistic analysis. Neologisms, twisted proverbs, word games, to name just a few, have recently become popular techniques in advertising. No less popular are instances of paraphrased literary texts. Assuming that advertising is "a language in its own right not divorced from other cultural productions" (Skinner 1990: 315), as well as pointing to the fact that "advertisements use and modify the fragments of [literary] texts" (Gajewska 2009: 131, translation mine), advertising and literature might be viewed as mutually interacting discourses which, when mixed together, give a better chance to sell a given product.

This paper offers a linguistic analysis of an advertisement for

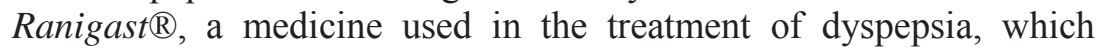
relies on a paraphrased fragment of The Sick Kitten, a famous Polish poem for children written by Stanisław Jachowicz. The proposed analysis of the advertisement will be carried out in the light of conceptual blending theory, in particular with the aid of Line Brandt and Per Aage Brandt's model of conceptual integration (Brandt and Brandt 2005). Still, assuming that each advertisement is, to some extent, an interplay between the speaker and the hearer, a particular emphasis will be laid upon the complexity of the so-called Semiotic Base Space which serves as a "prerequisite for meaning construction" in the analyzed ad (Brandt and Brandt 2005: 225). For further elaboration of the Semiotic Base Space, which I consider of vital importance for an analyzed instance, Ronald Langacker's notion of Current Discourse Space (Langacker 2001) as well as Esther Pascual's notions of the Verbal Space and Here-and-Now Space (Pascual 2009) will also be taken into account. 
2. Conceptual integration: Old concepts and new approaches In one of the definitions of conceptual integration, the notion proposed and delineated by Gilles Fauconnier and Mark Turner (Fauconnier and Turner 1998, 2002, also Fauconnier 2012, Turner 1996), we read (Fauconnier 2012: 50):

Conceptual integration (blending) is a basic mental operation that leads to new meaning, global insight, and conceptual compressions useful for memory and manipulation of otherwise diffuse ranges of meaning. It plays a fundamental role in the construction of meaning in everyday life, in the arts and sciences, in mathematics and in religious thought. The essence of the operation is to construct a partial match between inputs, to project selectively from those inputs into a novel "blended" mental space, which then dynamically develops emergent structure.

Thus defined, conceptual blending is viewed as a universal allembracing mechanism that helps to account for all cognitive operations that occur in the human mind. ${ }^{1}$ Still, a universal and ubiquitous character of Fauconnier and Turner's 'silver-bullet' theory runs the risk of being "too powerful, accounting for everything and explaining nothing" (Gibbs 2000, after Coulson and Oakley 2000: $186,192)$ when scrutinized in detail. ${ }^{2}$ The inadequacies of the original model of conceptual integration have been pinpointed by numerous scholars (i.a. Li et al. 2012, Oakley and Coulson 2008, Veale and

1 The unquestionable position of conceptual blending among other cognitive operations of the human mind is also emphasised by Turner, who claims that "at the most basic levels of perception, of understanding and of memory, blending is fundamental" (Turner 1996: 11).

${ }^{2}$ Carl Bache compares the Fauconnier and Turner theory of conceptual integration with the silver bullet theory making the following observation: (Bache 2005: 1616):

When one reads the standard literature in conceptual integration theory (...) one easily gets the impression that blending is a mechanism with silver-bullet qualities. Blending is simple, it is dynamic and powerful, if offers itself to elegant description, it seems to be a central factor in all mental activities, and it is arguably an important governing principle at all levels of human linguistic performance. 
O'Donoghue 2000, Libura 2010). For instance, Li et al. claim that the Fauconnier and Turner model lacks clearly specified mechanisms and procedures which come along the efficient construction of blends. In the opinion of the researchers, the Fauconnier and Turner approach leaves a lot of ambiguity in at least three pivotal procedures required at an in-depth description of the mechanism of blending. These concern: (i) the selection of input spaces, (ii) the selection of elements of projection, and (iii) the stopping criterion for blend elaboration $(\mathrm{Li}$ et al. 2012: 10).

But the problem with the Fauconnier and Turner approach does not confine solely to the inadequacies that arise while describing the mechanism of conceptual integration. Of equal importance is the lack of clear communication context required to fully account for the emerging blend. Assuming that Conceptual Blending Theory derives from its precursor, Mental Spaces Theory (Fauconnier 1994, 1997), it is impossible to detach the notion of mental spaces from the function they play in the dynamic process of conceptual integration, especially with reference to both contextual factors and the communication input in the meaning making process. Even a cursory glance at the definition of mental spaces, described as "small conceptual packets constructed as we think and talk, for purposes of local understanding and action" [that] "can be modified as thought and discourse unfold" (Fauconnier and Turner 2002: 40, 102, emphasis mine), leaves the reader unsatisfied as the definition does not fully explicate the context in which mental spaces are created, nor does it specify the role of the speaker-hearer interaction in blend creation.

The need to approach conceptual integration not only as the mechanism of online meaning construction, but, first and foremost, as a discourse-dependent process (Hart 2007) has been stressed by many cognitivists who view mental spaces as 'conversational units' created by the speakers, thus attempting to successfully link the theoretical assumptions of the Fauconnier and Turner model with elements of conversational analysis (CA) (Libura 2010: 143, also Hougaard and Oakley 2008, Cienki 2008, Oakley and Coulson 2008). Hougaard and 
Oakley, for instance, make the following observation (Hougaard and Oakley 2008: 14):

For CA researchers, the world is not seen as made up of individual minds; rather co-participants are seen as socially embedded from the outset and individual cognition is at best a secondary phenomenon of little interest to the practical sense that coparticipants create. For the notion of mental spaces to mean anything from an CA inspired perspective, it must, first and foremost, be thought of as a modeling of the observable jointly accomplished track of common sense not resident solely in each individual's mind.

The necessity to approach mental spaces as discourse-dependent elements which further influence conceptual integration is also postulated by Cienki, who emphasizes the importance of "the multimodal nature of in-person interaction" which enables us not only to see "cues of speakers setting up their own mental spaces", but also perceive "how the addressee may engage with them" (Cienki 2008: 239). Similarly, Oakley and Coulson claim that mental spaces should be defined as "representations of the scenes and situations in a given discourse scenario as perceived, imagined, remembered or otherwise understood by the speaker" (Oakley and Coulson 2008: 29).

In view of the above-mentioned inadequacies of the Fauconnier and Turner theory new revisions and extensions of the original model have emerged (cf. Brand and Brandt 2005, Oakley and Coulson 2008, Lidell 2003, Dancygier 2008). Of particular importance for the present paper is the revised model of conceptual integration as delineated by Brandt and Brandt (Brandt and Brandt 2005, also P.A. Brandt 2005, L. Brandt 2013), where the whole operation of conceptual integration has its roots in the very act of communication rather than remains a purely mental process (Libura 2010: 160). ${ }^{3}$ According to Brandt and Brandt,

\footnotetext{
${ }^{3}$ As noticed by Pascual, "cognitive linguists in general and conceptual blending scholars in particular have only recently started to include the overall situation of communication as part of their analyses" (Pascual 2009: 501). The group of scholars who also allow for contextual and communicative factors in the study upon mental spaces and conceptual integration include, besides Brandt and Brandt (2005), such linguists as Oakley and Coulson (2008), Libura (2010), Kardela (2007), and Liddell (2003).
} 
the presence of the speaker-hearer interaction gives us the possibility to observe "the conceptual process of interpretation" (Brandt and Brandt 2005: 219), for what a given blended unit means is "what it is intended to mean in a particular situation where it is uttered by someone" (Brandt and Brandt 2005: 219).

In its framework, the Brandt and Brandt model remains an extended version of the original four space integration network model as proposed by Fauconnier and Turner. It consists of six spaces: the Presentation Space, the Reference Space, the Virtual Space and the Meaning Space, both being two stages of blend elaboration, and, finally, two pragmatic elements, i.e. the Semiotic Space and the Relevance Space, which 'ground' the whole process of meaning construction in an appropriate communication context. ${ }^{4}$ The six-space integration network model is schematically presented in Figure 1.

\footnotetext{
${ }^{4}$ An interesting remark on the necessity of allowing for both the semiotic space and the relevance space in the process of conceptual integration as well as while decoding the blend meaning is expressed by Per Aage Brandt (Brandt 2005: 1588):

The hic et nunc awareness of present thinking is a 'self-remembering present', and a presently represented presence, that we experience - I suggest to stipulate through the mental space format. We also feel that other minds are using the same here-and-now space format while addressing us or attending to our own signs. The finite 'mental spatiality' of mental spaces, including the Base space of presently represented presence is a natural product of the mind's own design and therefore common to human minds and active in all situations of communication, in which minds can experience reciprocal attention.
} 


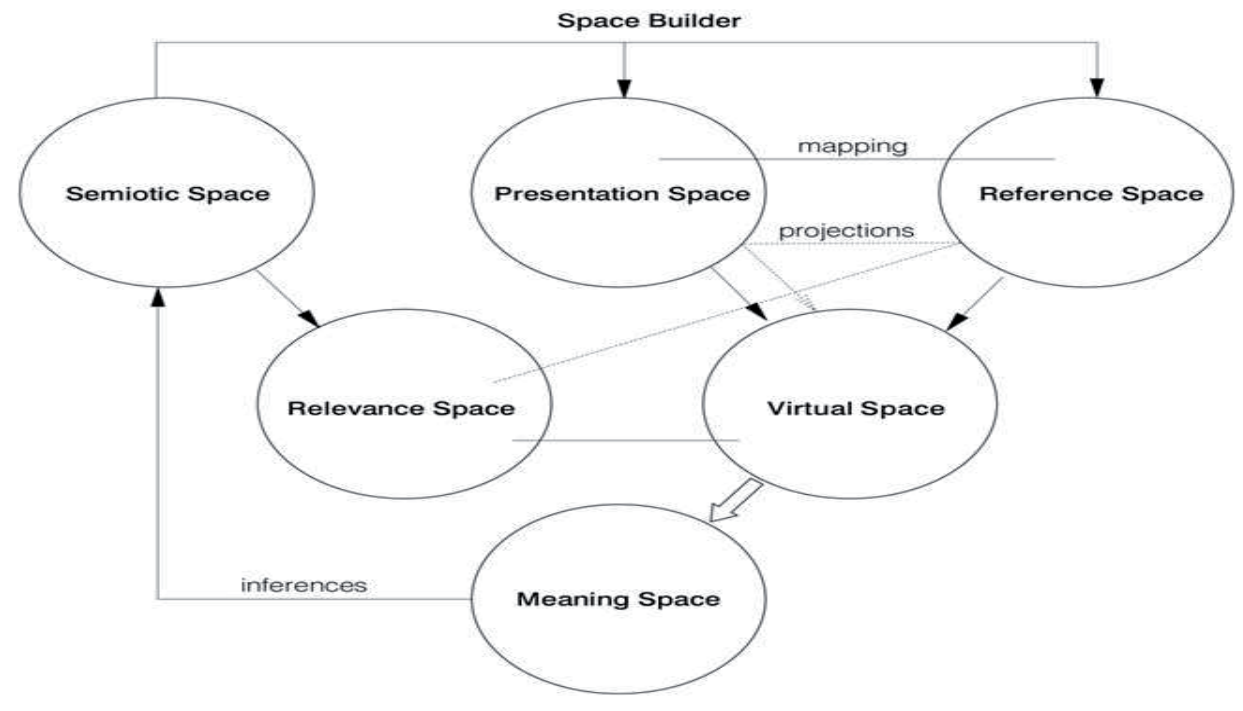

Figure 1. Brandt and Brandt's model (after Brandt and Brandt 2005: 235).

The details concerning the mechanism of the model as well as its application to the interpretation of the advertisement discussed herein will be presented in the subsequent part of this paper.

3. The Brandt and Brandt Model: An analysis

This part of the paper offers an in-depth analysis of a Polish advertisement for Ranigast ${ }^{\circledR}$ using the model delineated by Brandt and Brandt (Brandt and Brandt 2005). Simultaneously, while carrying out a linguistic analysis of the advertisement itself, further theoretical considerations on the six-space model of conceptual integration will also be presented. In particular, we will scrutinize the role of the speaker-hearer interaction comprised in the Semiotic Space and coupled with the Relevance Space, both contributing to a fuller picture 
of conceptual integration that is to be observed in the proposed analysis.

The empirical material for the analysis is an advertisement for Ranigast $\AA$, a medicine used in the treatment of dyspepsia and hyperacidity. The advertisement was broadcast on the Polish TV in the late $90 \mathrm{~s}$ of the $20^{\text {th }}$ century, gaining widespread acclaim. It presents two interlocutors, the patient and his neighbour, both talking about the ways to combat hyperacidity and dyspepsia. Both interlocutors use a paraphrased version of a very popular poem for children, Chory kotek (The Sick Kitten) written by Stanisław Jachowicz. The paraphrased literary text used in the advertisement is juxtaposed with the original version of the poem in Table 1.

Table 1: Paraphrased vs literary text of Chory kotek by Stanisław Jachowicz

\begin{tabular}{|c|c|}
\hline $\begin{array}{c}\text { Paraphrased literary text } \\
\text { (Ranigast }{ }^{\circledR} \text { ad, cf. Gajewska 2001: 131) }\end{array}$ & $\begin{array}{c}\text { Original literary text } \\
\text { (S. Jachowicz Chory Kotek, } \\
\text { Eng. transl. Antonia Lloyd- Jones } \\
\text { 2013) }\end{array}$ \\
\hline $\begin{array}{c}\text { Pan Kotek był chory } \\
\text { I leżał w łóżeczku. } \\
\text { I przyszedł Pan Sąsiad: } \\
\text { - Jak się masz, Koteczku? } \\
\text { - Niedobrze, oj, zgaga, nadkwaśność w } \\
\text { żolądku } \\
\text { - Ranigast weźmiesz i wszystko w } \\
\text { porządku! }\end{array}$ & $\begin{array}{l}\text { Pan Kotek był chory } \\
\text { i leżał w łóżeczku. } \\
\text { I przyszedł kot doktor. } \\
\text { - Jak się masz, koteczku? } \\
\text { - Źle bardzo- i lapkę } \\
\text { wyciągnąl do niego. }\end{array}$ \\
\hline
\end{tabular}

\footnotetext{
${ }^{5}$ The literary translation of the Polish poem delivered by Antonia. Lloyd-Jones (2013) goes as follows:

The cat was ill/And he lay in his bed, /Along came the doctor; /How are you? He said, /I'm poorly/Groaned puss, /as he held out a paw.
} 
The analysis will start with the reconstruction of the Semiotic (Base) Space, an element considered by Brandt and Brandt to be a "prerequisite for meaning construction" (Brandt and Brandt 2005: 225). In the proposed model, the Semiotic Space is defined by its authors as "a mental space in which the cognizer represents the present situation of cognizing" (Brandt and Brandt 2005: 225). In case of the proposed analysis, we are talking about the scene of communication in which two participants, i.e. the patient and the neighbour, are involved. Assuming, after Brandt and Brandt, that the communication situation should allow for three aspects while discussing both the situational context of the conversation and the very role of its participants, it is necessary to recall three types of elements that build the structure of the Semiotic Space. There include:

(i) semiosis - an expressive act of communication which embraces its participants engaged in the speech event,

(ii) situation, which entails the relevant circumstances surrounding the very speech event, both prior to it and its future implications,

(iii) pheno-world, i.e. the general knowledge the discourse participants have of the world (Brandt and Brandt 2005: 226).

In the light of the proposed analysis, in semiosis we find the dialogue between the patient and his neighbor. Situation illustrates here-and-now problems with indigestion, heat burn and hyperacidity, as well as gives an immediate solution to these problems. The third sphere, pheno-world, provides general knowledge upon health problems. Thus defined, the Semiotic Space becomes the basis for further elaboration of meaning.

Brandt and Brandt's Semiotic Space understood as a "representation of the speaker's act of engaging in meaning construction" (Brandt and Brandt 2005: 225) converges with Langacker's notion of Current Discourse Space (CDS), defined as the domain which comprises "those elements and relations construed as being shared by the speaker and hearer as a basis for communication" (Langacker 2001: 144). Being inextricably bound up with yet another 
term coined by Langacker, i.e. the notion of grounding understood as "the actual speech event, its participants, and its immediate circumstances" (Langacker 1999: 79), ${ }^{6}$ Current Discourse Space may successfully replace Brandt and Brandt's Semiotic Space in the proposed analysis as it clearly points out a direct interaction in communication between the interlocutors as well as further allows us to decode the blend, which, in the analysed instance, is the message hidden in the paraphrased literary text. ${ }^{7}$ Equally important for the proposed analysis may be the observation made by Pascual, who introduces the notion of Here-and-Now Space and Verbal Space (Pascual 2009). According to Pascual, Here-and-Now Space describes the context which occurs in the situation of ongoing communication, whereas Verbal Space is understood as the content of ongoing communication, or "the configuration set up by the verbal register of a communicative act" (Pascual 2009: 501). What ensues from the above-mentioned approaches allowing for the communicative context is the fact that this aspect cannot be overlooked once we want to carry out a successful analysis, whichever option is favoured.

Moving further in our analysis of the proposed ad, it is necessary to set up the Reference Space which refers to actuality (Brandt and Brandt 2005: 227). In the analysed instance, actuality is expressed by recalling a drug which helps combat dyspepsia and which, when necessary, is prescribed by the real doctor to the real patient. Ranigast ${ }^{\circledR}$ seems to be one of the widely recommended and reliable drugs for all kinds of indigestion, however, neither its efficiency nor the status of being the best choice for the patient are confirmed at this stage of the linguistic analysis. To arrive at the inferences which will

\footnotetext{
${ }^{6}$ According to Langacker, grounding involves: (i) the discourse participants and their roles, (ii) the immediate local context for the current communicative act, (iii) the situational relevance, and (iv) the argumentative relevance (Langacker 1999:79), and, as such, does resemble Brandt and Brandt's inner circle of the Semiotic space, namely semiosis.

${ }^{7}$ The attempt to replace Brandt and Brandt's Semiotic Space with Langacker's notion of Current Discourse Space was earlier proposed in the author's joint paper read at ICLC 2013 (see Mierzwińska-Hajnos and Augustyn 2013).
} 
allow us to view Ranigast ${ }^{\circledR}$ as the best remedy for indigestion, further steps in the analysis have to be undertaken. First of all, the Presentation Space has to be established. In the Presentation Space we find references to the original text of Chory kotek (The Sick Kitten) by Stanisław Jachowicz, where the qualities of the patient and the doctor are metaphorically transferred onto by the kitten and the cat, respectively. Next, selected elements from both the Presentation Space and the Reference Space are projected onto the first stage of blend, described by Brandt and Brandt as the Virtual Space, the characteristic feature of which "the very as-if-ness" (Brandt and Brandt 2005: 227). As observed by Brandt and Brandt, this stage of the blend is treated "as if it was real, and it yields real inferences, even though it is not vested with belief" (Brandt and Brandt 2005: 227). The "as-if-ness" of the Virtual Space manifests itself in recalling two interlocutors, i.e. $\mathrm{Mr}$ Kitten who suffers from dyspepsia and hyperacidity, and $\mathrm{Mr}$ Neighbour who behaves as if he were a genuine doctor recommending Ranigast ${ }^{\circledR}$ and, what follows, making simultaneously Mr Kitten a virtual patient. ${ }^{8}$

In our further endeavours to determine what the Virtual Space is supposed to mean, we need to recall a relevant framing. For this reason, the Relevance Space has to be activated, where all aspects of indigestion such as heartburn, nausea, upper abdominal fullness, belching as well as the methods to combat impaired digestion are recalled. The Relevance Space as introduced by Brandt and Brandt derives from the basic assumptions of the Relevance Theory as proposed by Sperber and Wilson (Sperber and Wilson 1995, also Wilson and Sperber 2012). As noticed by Wilson and Sperber (Wilson and Sperber 2012: 39),

\footnotetext{
${ }^{8}$ It has to be noted here the meaning of 'patient' is used when conceptualized in the context of doctor-patient relationship, both words being complementary. Therefore, the status of Mr Kitten as "the patient" presented in the proposed analysis may be viewed only as virtual. The same line of thought refers to the figure of Mr Neighbour who only gives a doctor's advice not being the doctor himself.
} 
Communicative principle of relevance provides the motivation for the comprehension procedure, which is automatically applied to the online processing of attended verbal inputs. The hearer takes the conceptual structure constructed by linguistic decoding; following a path of least effort, he enriches this at the explicit level and complements it at the implicit level, until the resulting interpretation meets his expectation of relevance; at which point, he stops.

In case of the proposed analysis, the relevant framing recalled in the Relevance Space gives the reader an opportunity to fully comprehend the blend at its final stage of development as well as to avoid false inferences while decoding it. When combined with Current Discourse Space and superimposed onto the Virtual Space, the Relevance Space contributes to the ultimate understanding of meaning expressed by the paraphrased text. By a long and convoluted interpretive process we finally reach the message of the ad which allows us to consider Ranigast ${ }^{\circ}$ as the best remedy for dyspepsia, the medicine that stands out among other pharmaceuticals available on the market. Thus, the very essence of the Meaning Space and the ultimate meaning is the very quality and efficiency of the medicine, the meaning which could not have been decoded but for a complicated mechanism of conceptual blending, ingeniously used by copywriters of the proposed ad.

The schematic interpretation of the ad is presented in Figure 2. 


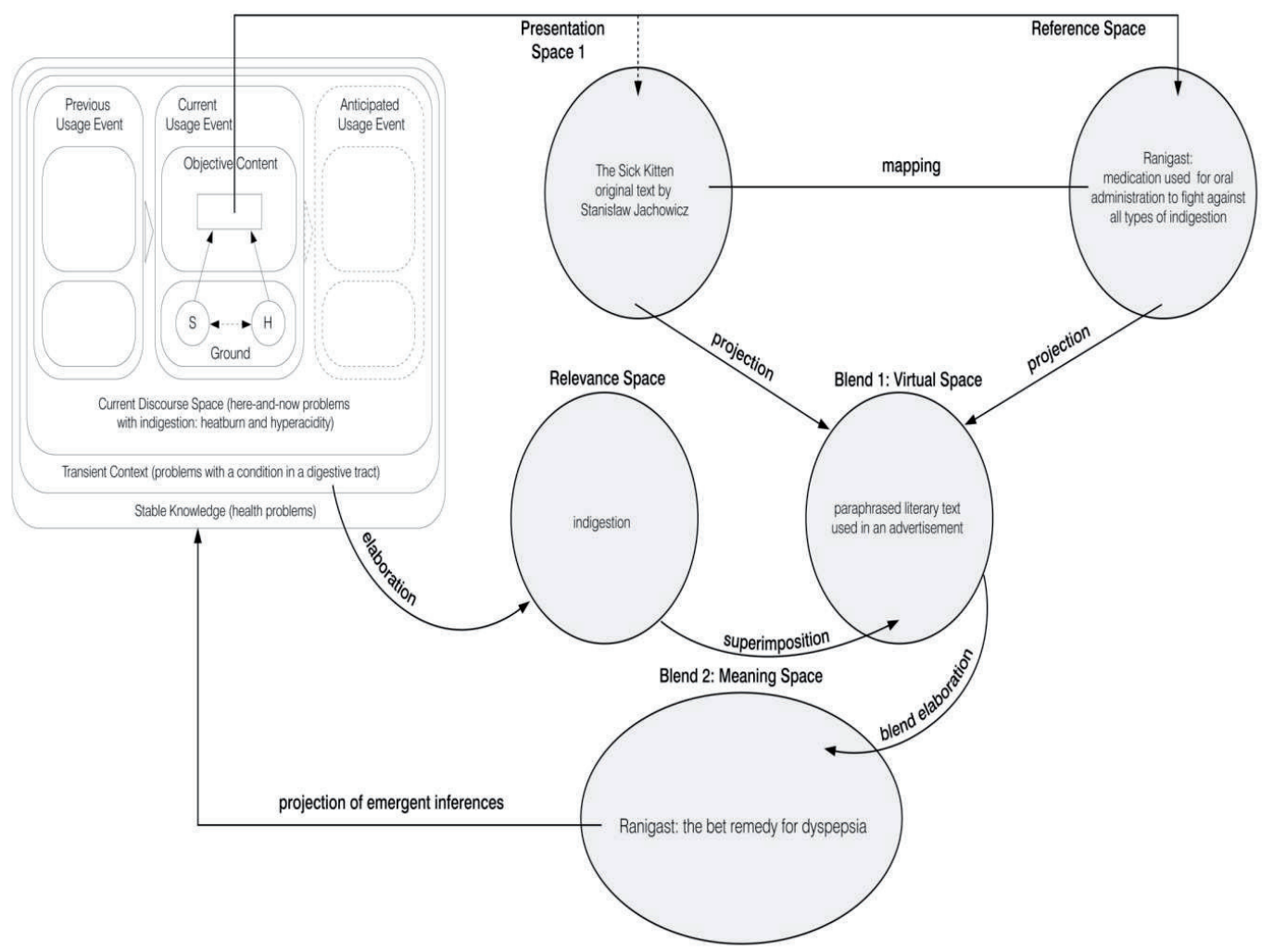

Figure 2. The linguistic analysis of the ad using the Brandt and Brandt model.

\section{Conclusions}

Conceptual blending is a complex mental operation, the legacy of which is eagerly applied in various areas, including advertising techniques. The proposed analysis aimed at portraying the way we approach an advertisement in which a paraphrased literary text serves as the basis for further decoding of the ultimate conceptual blend. 
Still, as it results from the above-mentioned study case, a successful conceptual blending analysis should not only focus on the blend as the ultimate product of conceptual integration, but should also scrutinize other stages of the blending process which greatly contribute to the overall reception of the message conveyed in the analysed ad. In particular, it should allow for the role of the speakerhearer interaction coupled with the relevant framing where the conversation between the two interlocutors is grounded in the relevant context, further used in the process of blend elaboration.

For this reason, the original model of conceptual integration as proposed by its founding fathers, Gilles Fauconnier and Mark Turner, proves insufficient in such types of analysis as it neither introduces the interlocutors nor clearly explicates the role of context while decoding the blend: all we know from the Fauconnier and Turner model is that the whole process of conceptual blending is always context-dependent and dynamic (cf. Fauconnier and Turner 2002). However, the way we approach this context and boost the dynamicity of blending remains vague.

For this reason, in lieu of the original Fauconnier and Turner model of conceptual blending, the six-space model developed by Brandt and Brandt has been applied to account for intricate nuances hidden behind the paraphrased literary text exchanged by the two interlocutors, the participants of the analysed ad. Introducing the socalled Semiotic Base Space as well as the Relevance Space, Brandt and Brandt aim at unique interpretation of the conceptual blend which is deeply rooted in a clearly established context, additionally induced by the speaker and the hearer. To become even more precise in further considerations pointing to the most accurate interpretation of the blend, the author of the proposed paper has decided to replace Brandt and Brandt's Semiotic Base Space with Langacker's notion of Current Discourse Space.

Still, to prove that thus modified Brandt and Brandt's model might serve as a universal framework to decode each and every conceptual blend that occurs in a given context and within a given conversation would be an oversimplification if not 'linguistic dilettantism'. 
Therefore, further insights and revisions in this field are required, for instance the one that will scrutinize the role of Here-and-Now Space and the Verbal Space as elaborated by Pascual and only hinted at in the proposed paper.

\section{References}

Bache, C. (2005). Constraining Conceptual Integration Theory. Levels of blending and disintegration. Journal of Pragmatics 37, 1615-1635.

Bralczyk, J. (2004). Język na sprzedaż. Gdańsk: Gdańskie Wydawnictwo Psychologiczne.

Brandt, L. (2013). The Communicative Mind: A Linguistic Exploration of Conceptual Integration and Meaning Construction. Newcastle upon Tyne: Cambridge Scholars Publishing.

Brandt, P. A. (2005). Mental Spaces and cognitive semantics: A critical comment. Journal of Pragmatics 37, 1578-1594.

Brandt, L., \& P.A. Brandt (2005). Making sense of a blend: A cognitive-semiotic approach to metaphor. Annual Review of Cognitive Linguistics 3, 216-249.

Cienki, A. (2008). Looking at analysis of mental spaces and blending/ Looking at and experiencing discourse in interaction. In: T. Oakley and A. Hougaard (eds.), Mental Spaces in Discourse and Interaction. Amsterdam-Philadelphia: John Benjamins, 235-245.

Coulson, S., \& T. Oakley (2000). Blending basics. Cognitive Linguistics 11(3/4), $175-$ 196.

Dancygier, B. (2008). The text and the story: Levels of blending in fictional narratives. In: T. Oakley and A. Hougaard (eds.), Mental Spaces in Discourse and Interaction. Amsterdam-Philadelphia: John Benjamins, 51-78.

Fauconnier, G. (1994). Mental Spaces: Aspects of Meaning Construction in Natural Language. Cambridge and New York: Cambridge University Press.

Fauconnier, G. (1997). Mappings in Thought and Language. Cambridge and New York: Cambridge University Press.

Fauconnier, G. (2012). Ten Lectures on Cognitive Construction of Meaning. Beijing: Foreign Language Teaching and Research Press.

Fauconnier, G., \& M. Turner (1998). Conceptual Integration Networks. Cognitive Science 22(2), 133-187.

Fauconnier, G., \& M. Turner (2002). The Way We Think: Conceptual Blending and the Mind's Hidden Complexities. New York: Basic Books.

Gajewska, E. (2011). Językowe gry nadawcy z odbiorcą we współezesnym dyskursie reklamy. Media i Społeczeństwo 1, 126-132. 
Hart, C. (2007). Critical Discourse Analysis and conceptualization: Mental spaces, blended spaces and discourse spaces in the British National Party. In: C. Hart and D. Lukeš (eds.), Cognitive Linguistics in Critical Discourse Analysis. Newcastle: Cambridge Scholars Publishing, 107-131.

Hougaard, A., \& T. Oakley (2008). Mental spaces and discourse analysis. In: T. Oakley and A. Hougaard (eds.), Mental Spaces in Discourse and Interaction. Amsterdam-Philadelphia: John Benjamins, 1-26.

Kardela, H. (2007). 'Good' revisited: A mental space analysis. In: H. Kardela and A. Głaz (eds.), Further Insights into Semantics and Lexicography. Lublin: Wydawnictwo Uniwersytetu Marii Curie-Skłodowskiej, 291-303.

Langacker, R. W. (1999). Grammar and Conceptualization. Berlin, New York: Mouton de Gruyter.

Langacker, R. W. (2001). Discourse in cognitive grammar. Cognitive Linguistics 12(2), 143-188.

Li, B., Zook, A., Davis, N., \& M. O. Riedl (2012). Goal-driven conceptual blending: A computational approach for creativity. In: Proceedings of the 2012 International Conference on Computational Creativity, Dublin, Ireland. 3-16. Available online: www.cc.gatech.edu/ riedl/pubs/iccc12.pdf.

Libura, A. (2010). Teoria przestrzeni mentalnych i integracji pojęciowej: struktura modelu $i$ jego funkcjonalność. Wrocław: Wydawnictwo Uniwersytetu Wrocławskiego.

Liddell, S. K. (2003). Grammar, Gesture and Meaning in American Sign Language. Cambridge: Cambridge University Press.

Mierzwińska-Hajnos, A., \& R. Augustyn (2013). A note on the generic space: Do we really need it? Paper read at 12th International Cognitive Linguistics Conference, University of Alberta, Edmonton, Canada.

Oakley, T., \& S. Coulson (2008). Mental spaces and metaphoric language in discourse. In: T. Oakley and A. Hougaard (eds.), Mental Spaces in Discourse and Interaction. Amsterdam-Philadelphia: John Benjamins, 27-50.

Pascual, E. (2009). "I was in that room!": Conceptual integration of content and context in a writer's vs. a prosecutor's description of a murder. In: V. Evans and S. Pourcel (eds.), New Directions in Cognitive Linguistics. Amsterdam: John Benjamins, 499-516.

Skinner, E. (1990). Advertising fictions: Literature, advertisement, and social reading (review). MFS Modern Fiction Studies 36(2), 315-316.

Sperber, D., \& D. Wilson (1995). Relevance: Communication and Cognition. Oxford: Blackwell.

Turner, M. (1996). The Literary Mind: the Origin of Thought and Language. New York: Oxford University Press.

Veale, T., \& D. O'Donoghue (2000). Computation and blending. Cognitive Linguistics 11, 253-281.

Wilson, D., \& D. Sperber (2012). Meaning and Relevance. Cambridge: Cambridge University Press. 